
\title{
$\begin{array}{ll}\text { Research Square } & \text { Preprints are preliminary reports that have not undergone peer review. } \\ \text { They should not be considered conclusive, used to inform clinical practice, } \\ \text { or referenced by the media as validated information. }\end{array}$
}

\section{Efferent and Afferent Connections of the Supratrigeminal Neurons Conveying Orofacial Muscle Proprioception in Rats}

\section{Atsushi Yoshida ( $\square$ yoshida@dent.osaka-u.ac.jp ) \\ Osaka University Graduate School of Dentistry \\ Misaki Inoue}

Department of Oral Anatomy and Neurobiology, Graduate School of Dentistry, Osaka University, Suita, Osaka 565-0871, Japan

\section{Fumihiko Sato}

Department of Oral Anatomy and Neurobiology, Graduate School of Dentistry, Osaka University, Suita, Osaka 565-0871, Japan

\section{Yayoi Morita}

Department of Oral Anatomy and Neurobiology, Graduate School of Dentistry, Osaka University, Suita, Osaka 565-0871, Japan

\section{Yumi Tsutsumi}

Department of Oral Anatomy and Neurobiology, Graduate School of Dentistry, Osaka University, Suita, Osaka, 565-0871, Japan

\section{Takahiro Furuta}

Department of Oral Anatomy and Neurobiology, Graduate School of Dentistry, Osaka University, Suita, Osaka 565-0871, Japan

\section{Katsuro Uchino}

Department of Acupuncture, Takarazuka University of Medical and Health Care, Takarazuka, Hyogo 6660162, Japan

\section{Fatema Akhter}

College of Dentistry, Dar Al Uloom University, Riyadh 11512, Kingdom of Saudi Arabia

\section{Yong Chul Bae}

Department of Anatomy and Neurobiology, School of Dentistry, Kyungpook National University, Daegu 700-412, Korea

\section{Yoshihisa Tachibana}

Department of Physiology and Cell Biology, Kobe University Graduate School of Medicine, Kobe Hyogo 650-0017, Japan

\section{Tomio Inoue}

Department of Oral Physiology, Showa University School of Dentistry, Shinagawa-ku, Tokyo 142-8555, Japan 


\section{Research Article}

Keywords: Muscle spindle, Mastication, Swallowing, Neuronal tracer, BDA, CTb

Posted Date: June 21st, 2021

DOl: https://doi.org/10.21203/rs.3.rs-616812/v1

License: (c) (i) This work is licensed under a Creative Commons Attribution 4.0 International License. Read Full License

Version of Record: A version of this preprint was published at Brain Structure and Function on October 5th, 2021. See the published version at https://doi.org/10.1007/s00429-021-02391-9. 


\section{Abstract}

The supratrigeminal nucleus (Su5) is a key structure for controlling jaw-movements since it receives proprioceptive sensation from jaw-closing muscle spindles (JCMSs) and sends projection to the trigeminal motor nucleus (Mo5). However, the central projection and regulation of JCMS proprioceptive sensation have not been fully understood. Therefore, we aimed to reveal the efferents and afferents of the Su 5 by means of neuronal tract tracings. Anterograde tracer injections into the Su5 revealed that the Su5 sent contralateral projections (or bilateral projections with a contralateral predominance) to the Su5, basilar pontine nuclei, pontine reticular nucleus, deep mesencephalic nucleus, superior colliculus, caudoventromedial edge of ventral posteromedial thalamic nucleus, parafascicular thalamic nucleus, zona incerta, and lateral hypothalamus, and ipsilateral projections (or bilateral projections with an ipsilateral predominance) to the intertrigeminal region, trigeminal oral subnucleus, dorsal medullary reticular formation, and hypoglossal nucleus as well as the Mo5. Retrograde tracer injections into the Su5 demonstrated that the Su5 received bilateral projections with a contralateral predominance (or contralateral projections) from the primary and secondary somatosensory cortices, granular insular cortex and Su5, and ipsilateral projections (or bilateral projections with an ipsilateral predominance) from the dorsal peduncular cortex, bed nuclei of stria terminalis, central amygdaloid nucleus, lateral hypothalamus, parasubthalamic nucleus, trigeminal mesencephalic nucleus, parabrachial nucleus, juxtatrigeminal region, trigeminal oral and caudal subnuclei, and dorsal medullary reticular formation. These findings suggest that the Su5 receiving JCMS proprioceptive sensation has efferent and afferent connections with multiple brain regions, which are involved in emotional and autonomic functions as well as orofacial motor functions.

\section{Introduction}

Proprioceptive signals arising from muscles in the entire body play a crucial role in sensorimotor reflexes through the reflex arcs located at the levels of the lower brainstem or the spinal cord. For instance, the proprioceptive signals arising from jaw-closing muscle spindles (JCMSs) are conveyed by primary afferents, whose neuronal cell bodies are located in the trigeminal mesencephalic nucleus (Me5), to the jaw-closing motoneurons in the trigeminal motor nucleus (Mo5) in the rostral pons (Luo et al. 1995, 2001; Fujio et al. 2016; for review, see Dubner et al. 1978; Taylor 1990); this monosynaptic reflex arc induces jaw-jerk reflex (a kind of stretch reflex). The JCMS proprioceptive signals are also transmitted by the Me5 primary afferents to the supratrigeminal nucleus (Su5) in the rostral pons (Jerge 1963; Takata and Kawamura 1970; Miyazaki and Luschei 1987). The Su5 contains excitatory or inhibitory premotoneurons projecting to the jaw-closing or -opening motoneurons in the Mo5 (Ohta and Moriyama 1986; Nakamura et al. 2008; Paik et al. 2009; Nonaka et al. 2012). Accordingly, the JCMS proprioceptive sensation conveyed by the Me5 primary afferents can induce the reflexive jaw-closing via the direct pathway to the Mo5, and facilitate (or suppress) the reflexive jaw-closing or -opening via the indirect Su5-Mo5 pathways (Goldberg and Nakamura 1968; Kidokoro et al. 1968; Ohta and Moriyama 1986; Shigenaga et al. 1988b, 1990). 
Although the functional connectivity via the Me5-Su5-Mo5 in the jaw reflex arc has been well studied as above, the central processing and regulation of orofacial proprioception arising from masticatory muscle spindles remain unknown. We have revealed that the Me5 afferents transmit the sensory signals almost exclusively from the JCMSs, but rarely from the periodontal ligaments around upper and lower teeth in the rat (Fujio et al. 2016). This finding indicates that the efferent projections from the rat Su5 specifically signals the JCMS proprioception. The Me5 neurons transmitting the JCMS proprioceptive signals do not send direct projections to the thalamus (e.g. Shigenaga et al. 1988a, 1989, 1990; Luo et al. 1995, 2001; Fujio et al. 2016), whereas the Su5 conveys the JCMS proprioceptive signals to the thalamus (Yoshida et al. 2017). We should note that the thalamic projection site of the Su 5 is restricted in a small area of the ventral posteromedial thalamic nucleus (VPM), caudo-ventromedial edge of the VPM (VPMcvm), which is different from the "traditional" core VPM conveying the orofacial cutaneous/mucosal sensation (Yoshida et al. 2017). The Su5 also projects, to a lesser extent, to the oval paracentral nucleus (OPC) in the intralaminar thalamic nuclei (Yoshida et al. 2017; Sato et al. 2020). The JCMS proprioceptive signals via the VPMcrm are subsequently conveyed to the dorsal part (dGIrvs2) of the granular insular cortex (GI) rostroventrally adjacent to the rostralmost part of the secondary somatosensory cortex (S2), whereas the signals via the OPC to the rostral part of the primary somatosensory cortex (S1), the rostral S2, and the rostral GI (Sato et al. 2017; Tsutsumi et al. 2021). These cortical projection pathways strongly suggest that the JCMS proprioceptive signals are more involved in emotional function than sensory discriminative and motor functions. However, it remains unknown which higher brain regions outside the thalamus receive the JCMS proprioception via the Su5. This information is very important to fully understand the brain networks required for neuronal processing of orofacial proprioception. Therefore, in the first experiment, we sought to reveal efferent projections of the Su 5 in the entire brain by means of anterograde tracer injections into the rat Su5.

Besides the relay neurons ascending to higher brain regions (e.g. VPMcvm and OPC), the Su5 also contains premotoneurons for reflexive jaw movements (Li et al. 1995; Ohta and Moriyama 1986; Nakamura et al. 2008; Paik et al. 2009; Yoshida et al. 2009; Nonaka et al. 2012). Therefore, another important issue is which brain regions send neuronal information that can modulate the reflexive jawmovements. Previous studies have shown that the Su5 receives projections from the cortical regions such as the GI (Sato et al. 2013; Ikenoue et al. 2018), the S1 (Hattox et al. 2002; Chang et al. 2009; Yoshida et al. 2009; Tomita et al. 2012), and the lateral agranular cortex (Agl; Yoshida et al. 2009), and subcortical regions such as the bed nucleus of stria terminalis (BST; Dong and Swanson 2003), the parvocellular reticular formation (Ter Horst et al. 1991), and the solitary tract nucleus (Sol; Oka et al. 2013). However, it remains unsolved whether the other brain regions outside these structures send projections to the Su5. In addition, it is also unknown which brain regions have reciprocal connections with the Su5, which can form regulatory feedback loops. Thus, in the second experiment, we sought to reveal afferent projections of the Su 5 in the entire brain by means of retrograde tracer injections into the rat Su5.

\section{Materials And Methods}




\section{Animals}

The experiments described here were performed on 19 male Wistar rats weighing $250 \mathrm{~g}-340 \mathrm{~g}$. All experimental procedures were approved by the animal ethics committees of the Osaka University Graduate School of Dentistry for the care and use of laboratory animals, and the experiment was performed in accordance with the relevant guidelines. Efforts were made to minimize animal suffering and the number of animals used.

\section{Surgery, recordings, and tracer injections}

All animals used were anesthetized by intraperitoneal administration of ketamine hydrochloride (90 $\mathrm{mg} / \mathrm{kg}$ ) and xylazine hydrochloride $(10 \mathrm{mg} / \mathrm{kg}$ ) dissolved in saline, with supplementary doses given such that neither spontaneous eye movements nor corneal reflexes were apparent. A local injection of lidocaine hydrochloride was administered before making a skin incision if necessary. The rectal temperature was maintained between $37^{\circ} \mathrm{C}$ and $38^{\circ} \mathrm{C}$ with a heating pad, and electrocardiography was performed continuously. Rat brain atlases published by Swanson (2004) or Paxinos and Watson (1998, 2014) were used to determine the coordinates for stereotaxic micropipette insertion.

We aimed to extracellularly inject an anterograde tracer (in the first experiment) and a retrograde tracer (in the second experiment) into the left Su5 that was electrophysiologically identified. To this end, an incision was made in the buccal skin to expose the left masseter muscle, and the left masseter nerve (which innervates JCMSs) was dissected so that it was free from the surrounding masseter muscle. Then, silver bipolar stimulation hook electrodes were positioned on the masseter nerve to enable electrical stimulation (single pulse, 200- $\mu$ s duration, $1 \mathrm{~Hz}$ ). After the initial surgery, the animal's head was placed in a stereotaxic apparatus.

As in our previous study (Yoshida et al. 2017; Sato et al. 2020), after craniotomy, a glass micropipette filled with $2.0 \mathrm{M}$ potassium citrate was inserted into the left Su5 obliquely with an $18^{\circ}$ rostral-to-caudal inclination to the coronal plane. To precisely locate the left Su5, field potentials responding to electrical stimulation of the left masseter nerve as well as to passive, sustained jaw-opening movements were recorded. Then, the glass micropipette was changed to one filled with an anterograde tracer, biotinylated dextranamine (BDA, 10,000 MW, Molecular Probes, Eugene, OR, USA) dissolved in saline in the first experiment, or to one filled with a retrograde tracer, $1 \%$ cholera toxin $B$ subunit (CTb; List Biological Laboratories, Campbell, CA, USA) dissolved in 0.02 M phosphate-buffered saline (PBS, pH 7.4) in the second experiment, in order to reinsert into the Su5. Signals recorded from the microelectrode were amplified, filtered ( $300 \mathrm{~Hz}$ to $3 \mathrm{kHz}$ ), and stored in a computer at the sampling rate of $20 \mathrm{kHz}$ (field potentials) or $10 \mathrm{kHz}$ (unit activity). Subsequently, BDA or CTb was extracellularly injected into the Su5 with electrophoresis (delivering 2.0- $\mu \mathrm{A}$ positive, $300 \mathrm{~ms}$ duration pulses, at $2 \mathrm{~Hz}$, for 3-7 min). After the tracer injection, the glass microelectrode was carefully withdrawn, and the stimulation electrodes were detached from the masseter nerve. All wounds were sutured. Then, an analgesic (flurbiprofen axetil, 3.3 $\mathrm{mg} / \mathrm{kg}$ ) and an antibiotic (cefotiam hydrochloride, $66 \mathrm{mg} / \mathrm{kg}$ ) were intraperitoneally given, and the animals were allowed to recover from anesthesia in their cages. During the postinjection survival, the rats 
were monitored on a daily basis to assess general behaviors, body weight, and any postoperative complications such as bleeding or inflammation.

\section{Histology}

After a postinjection survival of 5-7 days, the rats were re-anesthetized deeply with an intraperitoneal injection of sodium pentobarbital ( $100 \mathrm{mg} / \mathrm{kg})$ and perfused with $100 \mathrm{ml}$ of $0.02 \mathrm{M} \mathrm{PBS}(\mathrm{pH} 7.4)$ followed by $300 \mathrm{ml}$ of a fixative containing $4 \%$ paraformaldehyde in $0.1 \mathrm{M}$ phosphate buffer ( $\mathrm{PB}, \mathrm{pH} 7.4)$ through the ascending aorta. Then, the entire brain was removed and placed in $25 \%$ sucrose in $0.02 \mathrm{M} \mathrm{PB}$ at $4^{\circ} \mathrm{C}$ for a few days. It was cut coronally at $60 \mu \mathrm{m}$ thick on a freezing microtome. The serial sections were alternately divided into three sets.

For the detection of BDA in the first experiment, all sets of alternate serial sections were washed in $0.02 \mathrm{M}$ PBS (pH 7.4) and preincubated in $0.02 \mathrm{M}$ PBS containing $0.01 \% \mathrm{H}_{2} \mathrm{O}_{2}$ and $0.75 \%$ Triton $\mathrm{X}-100$, as described previously (Sato et al. 2013; Akhter et al. 2014). For visualization of CTb in the second experiment, all section sets were preincubated in $0.02 \mathrm{M}$ PBS containing $3 \%$ normal goat serum, $0.2 \%$ Triton X-100 and a polyclonal rabbit anti-CTb primary antibody (List Biological Laboratories, USA) diluted to 1:40,000, as described previously (Uemura et al. 2020). Then, the sections were incubated in $0.02 \mathrm{M}$ PBS containing biotinylated goat anti-rabbit immunoglobulin $\mathrm{G}$ diluted to 1:400. Subsequently, all sections in all cases with BDA or CTb injections were incubated in $0.02 \mathrm{M}$ PBS containing avidin-biotinperoxidase complex diluted at 1:100, and were then reacted in a diaminobenzidine solution (0.1 M PB [pH 7.4] containing $0.04 \%$ diaminobenzidine, $0.006 \% \mathrm{H}_{2} \mathrm{O}_{2}$ and $0.08 \%$ nickel ammonium sulfate). They were mounted on gelatin-coated slides and dried. One set of sections was counterstained with Thionin or Neutral Red. Then, all of the sections were dehydrated in graded alcohols, cleared in xylene, and coverslipped.

\section{Data analysis}

The field potentials recorded in and around the Su 5 were stored on a computer, and offline analysis was performed with computer assistance (PowerLab 8/30, ADInstruments, Sydney, Australia). Responses to six to nine successive peripheral stimuli were averaged at each recording site. By use of a camera lucida attached to a light microscope, we drew the brain structures, BDA injection sites, anterogradely BDAlabeled axonal fibers and terminals, CTb injection sites, and retrogradely CTb-labeled neuronal cell bodies, all of which were found in the entire brain except for the cerebellum.

\section{Results}

\section{Tracer injections into the Su5}

In the first experiment, we sought to examine the detailed distribution of anterograde projections from the Su5 to the entire brain except for the cerebellum. First, to identify the Su5 as in our previous studies (Fujio et al. 2016; Yoshida et al. 2017; Sato et al. 2020), we recorded the field potentials responding to electrical 
stimulation of the ipsilateral masseter nerve (innervating JCMS receptors) with short latencies (e.g. Fig. 1a). At the same recording site, we also recorded unit discharges during passive, sustained jaw-opening (e.g. Fig. 1b). We, then, injected an anterograde tracer BDA into the recording site in the Su5 by means of an electrophoretic procedure in ten rats (Fig. 1c, d).

In the second experiment, we sought to analyze the detailed distribution of origin neurons projecting to the Su 5 from the entire brain except for the cerebellum. As in the first experiment, after electrophysiological identification of the Su5 (e.g. Fig. 1a, b), we injected a retrograde tracer CTb into the recording site in the Su5 by means of an electrophoretic procedure in nine rats (Fig. 1e, f).

Subsequently, in both the first and second experiments, we histologically confirmed the exact location of BDA and CTb deposits. We cytoarchitectonically delineated the Su5 as in our previous studies (Fujio et al. 2016; Yoshida et al. 2017; Sato et al. 2020); the center of the Su5 was located approximately $2.4 \mathrm{~mm}$ lateral, $9.7 \mathrm{~mm}$ caudal, and $7.6 \mathrm{~mm}$ ventral to the bregma. Note that the location of the Su 5 seemed mostly equivalent to that described by Torvik (1956) or by Swanson (2004), but seemed to be located more caudolaterally than that described in the atlases by Paxinos and Watson $(1986,1998,2014)$ (see the Discussion section for more detailed explanation). In the present study, the BDA and CTb deposits were successfully confined to the Su5 without extending into the structures surrounding the Su5 in three rats each (Figs. 1c-f, 4i).

\section{Distribution of BDA-labeled terminals}

In all of the three rats (R116, R621, R810) in the first experiment, the anterogradely BDA-labeled axons showed similar distribution patterns (Figs. 2-4). Hereafter, we first describe the distribution pattern in rostral sections and then state the pattern in caudal sections in a representative case (R621). On the contralateral side of the mesencephalic region immediately rostral to the injection (Fig. $3 \mathrm{~h}$ ), a large number of BDA-labeled axon terminals emitting from stem axons labeled in the trigeminothalamic tract (tth) were observed in a small area of the basilar pontine nuclei (BPn) ventral to the longitudinal fasciculus (If) (also Fig. 5d), whereas a small number of terminals were detected in the reticulotegmental nucleus ( $\mathrm{RtTg}$ ) dorsal to the tth. A moderate number of axon terminals were also seen in the pontine reticular nucleus $(\mathrm{PnR})$ bilaterally with a contralateral predominance. In addition, a small number of axon terminals were labeled bilaterally in the rostral parabrachial nucleus $(\mathrm{Pb})$.

In the more rostral mesencephalon (Fig. 3g), on the contralateral side, labeled axon fibers extended dorsolaterally in the deep mesencephalic nucleus ( $\mathrm{DpMe}$ ) and emanated a moderate number of labeled terminals in the DpMe. A moderate number of terminals were also labeled in the ventrolateral part of the contralateral superior colliculus (SC), mainly in its intermediate layer (also Fig. 5c). Few terminals were contralaterally labeled in the red nucleus (R), and bilaterally in the periaqueductal gray (PAG).

In the caudal diencephalon (Fig. 3f), a large number of labeled axon terminals were seen in the VPMcvm bilaterally with a clear contralateral predominance (also Fig. 5b). A moderate number of labeled axon terminals were contralaterally found in the parafascicular thalamic nucleus (Pf), the caudo-ventromedial 
part of the zona incerta (ZI) (Figs. 3e, f, 5a), and the caudo-dorsolateral part of the lateral hypothalamus (LH) medial to the $\mathrm{ZI}$ (Fig. 3e, f). A small number of labeled terminals were bilaterally seen in the OPC in the intralaminar thalamic nuclei with a contralateral predominance (Fig. 3e). No terminals were labeled in the amygdaloid complex (Figs. 2d, 3e, f). We also noted that no axon terminals were labeled in sections rostral to this level.

At the level of Su5 injection site (Fig. 4i), a large number of BDA-labeled axon terminals were found in the contralateral Su 5 (also Fig. 5e) and in the bilateral Mo5 with a striking ipsilateral predominance. Importantly, the distribution of axon terminals in the Mo5 concentrated in its dorsolateral division [so called jaw-closing motor nucleus $(\mathrm{JCm})]$, but rarely in the more caudal ventromedial division of the Mo5 [so called jaw-opening motor nucleus $(\mathrm{JOm})$ ]. In contrast, a small number of terminals were labeled only in the dorsolateral part of the contralateral $\mathrm{JCm}$. A large number of axon terminals were also labeled in the ipsilateral intertrigeminal region (I5) between the Su5 and the Mo5, but a fewer in the contralateral region. Few terminals were labeled in the other reticular formation around the Mo5, which included the reticular formation medial to the $\mathrm{JOm}$.

At the pontine level caudal to the Mo5 (Fig. 4j), a large number of labeled axon terminals were ipsilaterally seen in the rostro-dorsomedial part (5Or) of the oral subnucleus of the trigeminal spinal nucleus (50). At the more caudal pontine level where the facial nucleus (VII) appeared (Fig. 4k), a large number of axon terminals were ipsilaterally labeled in the juxtatrigeminal region (J5) in the lateral reticular formation medially adjacent to the 50. A moderate number of labeled axons were also seen in the dorsomedial part of 50 bilaterally with an ipsilateral predominance. A small number of terminals were also labeled in the lateral part of the ipsilateral VII (also Fig. 5f).

At the level of the rostral medulla (Fig. 4I), a large number of labeled axons were observed in the dorsal medullary reticular formation (dmRf) ventral to the Sol (also Fig. $5 \mathrm{~g}$ ), and extended laterally to the J5 medial to the dorsomedial part of the interpolar subnucleus of the trigeminal spinal nucleus (5I); the distribution pattern was observed bilaterally with a clear ipsilateral predominance. In addition, the labeled terminals were also seen in the rostro-ventrolateral part of the ipsilateral Sol (Fig. 4l, m). A small number of labeled terminals were ipsilaterally found in the paratrigeminal nucleus (Pa5) (Figs. 4l, 5h), which denotes both "paratrigeminal" and "dorsal Para marginal" interstitial nuclei defined by Phelan and Falls (1989). More caudally, at the medullary level including the obey (Fig. 4m), a large number of labeled axons appeared in the dmRf lateral to the hypoglossal nucleus (XII), and continued to the J5 medial to the rostro-dorsomedial part of the caudal subnucleus of the trigeminal spinal nucleus (5C); the distribution pattern was bilateral with a clear ipsilateral predominance. The axon terminals were also seen in the XII bilaterally with an obvious ipsilateral predominance (also Fig. 5i). In addition, a small number of terminals were ipsilaterally labeled in the dorsomedial edge of the $5 \mathrm{C}$. At the caudal $5 \mathrm{C}$ level (Fig. 4n), a moderate number of terminals were almost ipsilaterally labeled in the reticular formation, ventral to the cuneate nucleus $(\mathrm{Cu})$ and medial to the caudal $5 \mathrm{C}$.

\section{Distribution of CTb-labeled neuronal cell bodies}


In all three rats (R303, R310, R214) in the second experiment, the retrogradely labeled neuronal cell bodies (hereafter termed "neurons") after CTb injections into the Su5 showed similar distribution patterns in the entire brain. In a representative rat (R303), the distribution pattern of cortical labeling was bilateral with a contralateral predominance (except for the dorsal peduncular cortex, DP) (Fig. 2a-c). Most rostrally (Fig. 2a), a small number of labeled neurons were seen in the rostralmost level of the Agl, but a fewer in the medial agranular cortex (Agm) and the agranular insular cortex (Al). More caudally (Fig. 2b), a large number of labeled neurons appeared in the ventral part of the rostral S1 (also Fig. 6a) and its ventral vicinity in the rostral GI (also Fig. 6b). At more caudal level (Fig. 2c), a moderate number of neurons were also labeled in the rostral S2 and its ventral vicinity in the GI. Almost all of the labeled cortical neurons were situated in the inner part (layer $\mathrm{Vb}$ ) of cortical layer $\mathrm{V}$. In addition, a small number of neurons were labeled in layer VI of the DP, but this distribution was uniquely observed on the ipsilateral side.

Most rostrally in subcortical structures (Fig. 2c), a moderate number of CTb-labeled neurons were ipsilaterally found in the lateral part of rostrocaudally middle level of the BST, which seemed to include the rhomboid subnucleus of the BST denoted by Swanson (2004). At the slightly caudal level (Fig. 2d), a large number of neurons were ipsilaterally labeled in the rostral level of the central amygdaloid nucleus (AmC), especially its medial division (also Fig. 6c), whereas a fewer in the paraventricular hypothalamic nucleus $(\mathrm{PvH})$, especially in its medial parvicellular part (also Fig. $6 \mathrm{~d}$ ). More caudally, a moderate number of labeled neurons ipsilaterally appeared in the caudal level of the dorsolateral part of $L H$, which caudally included the parasubthalamic nucleus (Psth) (Figs. 3e, f, 6e).

At the middle level of the mesencephalon (Fig. 3g), a small number of neurons were ipsilaterally labeled in the retrorubral field (RRF) (also Fig. 6f). At the levels from the middle mesencephalon to the rostral pons, a large number of labeled neurons were scattered rostrocaudally in the ipsilateral Me5 (Figs. $3 \mathrm{~g}, \mathrm{~h}$, 4i). At the same rostrocaudal level (Fig. 3h), a small number of neurons were scattered in the dorsal raphe nucleus (DR). Only in the ventrolateral part of the rostral $\mathrm{Pb}$, a moderate number of neurons were ipsilaterally labeled.

At the rostral pontine level (Fig. 4i), a moderate number of labeled neurons were observed in the Su5 contralateral to the $\mathrm{CTb}$ injection site (also Fig. $6 \mathrm{~g}$ ). Bilaterally with an ipsilateral predominance, a large number of neurons were labeled in the reticular formation ventral to the Mo5, and a fewer in the 15 between the Su5 and Mo5. Rare neurons were ipsilaterally labeled in the trigeminal principal nucleus (Pr5). At the pontine level between the Mo5 and the VII (Fig. 4j), only a small number of neurons were bilaterally labeled in the 50r and the $\mathrm{J} 5$ medial to the 50r. At the caudal pontine level where the VII appeared (Fig. 4k), a large number of labeled neurons were found in the dorsal part of the 50 and in the lateral reticular formation including the $\mathrm{J} 5$ medial to the 50 , bilaterally with an ipsilateral predominance.

At the level of the rostral medulla (Fig. 4l), a large number of neurons were labeled in the dmRf ventral to the Sol (also Fig. 6h), and the J5 medial to the dorsomedial part of the $5 \mathrm{l}$, bilaterally with a clear ipsilateral predominance. In addition, a small number of neurons were almost ipsilaterally labeled in the rostro-ventrolateral part of the Sol, the dorsomedial part of the 5I, and the Pa5 (also Fig. 6i). At the 
medullary level including the obey (Fig. $4 \mathrm{~m}$ ), a large number of labeled neurons appeared in the dorsal $5 \mathrm{C}$ bilaterally with a clear ipsilateral predominance; we note that these labeled neurons did not concentrate in the superficial layer of the $5 \mathrm{C}$ medially adjacent to the spinal trigeminal tract (sp5). Bilaterally with an obvious ipsilateral predominance, a large number of labeled neurons were also found in the $\mathrm{dmRf}$ ventral to the caudal Sol and in the J5 medial to the $5 \mathrm{C}$, whereas a fewer in the caudal Sol. At the caudal medullary level (Fig. 4n), a few neurons were almost ipsilaterally labeled in the $5 \mathrm{C}$ and the caudal Sol.

\section{Brain regions both receiving afferents from and sending efferents to the Su5}

Taken together, the data described above indicated that the brain structures both receiving afferents from and sending efferents to the Su5 were located only at the rostrocaudal level of the Su5 and its more caudal levels (Fig. 4i-m). Such structures were the contralateral Su5, the bilateral I5 (Fig. 4i), the dorsomedial part of the ipsilateral 50 (Fig. 4k), the ipsilateral J5 medial to the 50 and $5 \mathrm{I}$ (Fig. 4k, I), the rostro-ventrolateral part of the ipsilateral Sol (Fig. 4l), the bilateral dmRf ventral to the Sol (Fig. 4l, m), and the ipsilateral Pa5 (Fig. 4l).

\section{Discussion}

The present study has demonstrated the detailed features of efferent and afferent projections of the Su5 in the entire brain (excluding the cerebellum). The rat Su5 sent outputs to and received inputs from multiple brain structures; some of them were overlapped. In the rostral brain, the Su 5 received cortical inputs from sensorimotor and dorsal insular cortices, whereas it also received subcortical inputs from limbic and autonomic structures such as the BST, LH, PvH, and AmC. In the caudal brain, the Su5 has strong reciprocal connections with motor structures required for controlling orofacial movements. The rat Su5 is known to almost exclusively receive the proprioception arising from the JCMSs (Fujio et al. 2016) among peripheral signals. Thus, it is highly likely that orofacial movements receive online feedback control of the orofacial proprioception via the Su5, which is influenced by higher brain regions related to sensorimotor, emotional, and autonomic functions.

Location of the Su5

The Su5 was first identified as an interneuron (premotoneuron) pool in the trigeminal reflex arc by Lorente de Nó $(1922,1933)$. Åström (1953) confirmed that the Su5 as well as the Mo5 receives axon collaterals of the Me5 primary afferents conveying the proprioceptive sensation from masticatory muscle spindles. Torvik (1956) defined the location of the rat Su5 as a dorsomedial extension of the rostro-dorsomedial part of the Pr5, but it is cytoarchitectonically distinguishable from the Pr5. Our present "Su5" was defined based on the electrophysiological responses to JCMS stimulation in addition to the cytoarchitectonic feature as in our previous studies (Fujio et al. 2016; Sato et al. 2017, 2020; Yoshida et al. 2017). In this respect, our Su 5 is located more caudolaterally than the Su 5 delineated in popular atlases by Paxinos and Watson $(1986,1998,2014)$, and almost corresponds to the Su5 defined by Torvik (1956) and Swanson (2004) (see Fujio et al. [2016] for the detailed differences between these two "Su5"). The connections of the rat Su5 have been studied based on the Paxinos and Watson's atlases in many earlier 
studies (e.g. Rokx et al. 1986; Shammah-Lagnado et al. 2001; Hattox et al. 2002; Mascaro et al. 2009; Papp and Palkovits 2014). Therefore, in this study, we aimed to reexamine the efferent and afferent connections of the electrophysiologically and cytoarchitectonically identified "real Su5", which receives the JCMS proprioception.

Afferent and efferent connections of the Su5 and their functional consideration

Connections with the pons and medulla. The present study has shown that the Su5 projects to the Mo5, mainly to the $\mathrm{JCm}$, bilaterally with a clear ipsilateral predominance. This Su5-Mo5 pathway has well been examined (Mizuno 1970; Donga et al. 1990; Yamamoto et al. 2007; Chang et al. 2009; Yoshida et al. 2009). Thus, the JCMS proprioceptive signals via the Su5 are considered to activate or inhibit the jawclosing or -opening motoneurons, which is confirmed by electrophysiological (Ohta and Moriyama 1986; Nakamura et al. 2008; Nonaka et al. 2012) and morphological studies (Paik et al. 2009). In the present study, the Su5 ipsilaterally projected to the VII and XII, suggesting that the JCMS proprioceptive signals via the Su5 also activate or inhibit the facial and tongue muscle contraction.

The Su5 bilaterally (with an ipsilateral predominance) projected to the five regions (the 15 , the dorsomedial 50, the J5 medially adjacent to the 50 and $5 \mathrm{l}$, the ventrolateral Sol, and the dmRf), which are known to contain premotoneurons projecting not only to the Mo5 but also to the VII, the XII or the ambiguus nucleus (containing motoneurons innervating the pharyngeal muscles) (Travers and Norgren 1983; Li et al. 1995; Cunningham and Sawchenko 2000; Yoshida et al. 2009; Oka et al. 2013; Stanek et al. 2014). These findings suggest that the JCMS proprioceptive signals via the Su5 activate or inhibit the facial, tongue, and pharyngeal muscle contraction as well as the jaw muscle contraction. Interestingly, the present study has also revealed that the Su 5 receives afferents from the five premotoneuron regions. Therefore, the jaw, facial, tongue and pharyngeal muscle contraction regulated by the JCMS proprioception via the Su5 may receive feedback control of the premotoneurons in the five regions. Accordingly, it is highly likely that the JCMS proprioceptive signals via the Su5 are involved in the coordination of mastication and swallowing. In addition, we have also revealed reciprocal connections between bilateral Su5. This commissural connection seems to contribute to the bilateral coordination of several muscle contraction during mastication and swallowing.

The present study has also revealed reciprocal connections between the Su5 and the ipsilateral Pa5. The Pa5 receives sensory inputs through the trigeminal nerve (Takemura et al. 1991), the glossopharyngeal nerve (Altschuler et al. 1989; Ma et al. 2007), and the superior laryngeal nerve (Oka et al. 2013), and noxious inputs from the orofacial tissues (e.g. tooth pulp and temporomandibular joint) (Zhou et al. 1999; Shimizu et al. 2006). Therefore, the JCMS proprioception via the Su5 may communicate with the cutaneous or deep sensation (including nociception) arising from other orofacial, pharyngeal, and laryngeal tissues.

Connections with the mesencephalon. It is of great importance that the Me5 primary afferents conveying the JCMS proprioception give off no axons that ascend towards the thalamus, and the Su 5 neurons are considered to receive the strongest projection from the Me5 afferents among all the secondary sensory 
neurons (Shigenaga et al. 1988a, 1989, 1990; Luo et al. 1995, 2001). These suggest that the JCMS proprioception might be transmitted to higher brain regions principally via the Su5.

At the level of mesencephalon, we have found a moderate projection from the Su5 to the contralateral SC, especially its intermediate layer. The Su5-SC pathway has been reported in an earlier study (Yasui et al. 1993), although the Su5 has not been precisely identified. The intermediate layer of the SC is known to receive projections from the substantia nigra pars reticulata as well as from the trigeminal sensory nuclear complex that transmits the orofacial sensation (including the muscle sensation of the external ocular muscles) excluding the JCMS proprioception (Porter and Donaldson 1991; Bickford and Hall 1992; Yasui et al. 1995; VanderWerf et al. 1997), and to project to head and eye movement-related regions (including the reticular formation around the Mo5) in the brainstem and spinal cord (Huerta and Harting 1984; Yasui et al. 1994). Thus, the Su5-SC pathway may influence the head and eye movements.

We have also demonstrated that the Su5 sends very dense and restricted projection to the BPn. The BPn is a major relay site of the cerebral cortical inputs to the cerebellar cortex (for review see Brodal 1982; Wiesendanger and Wiesendanger 1982). The BPn receives projections from the trigeminal sensory nuclear complex and spinal cord as well as the dorsal column nuclei (including external cuneate nucleus, which conveys proprioceptive signals from the neck and forelimb muscles) (Rosén and Sjölund 1973; Campbell et al. 1974; Swenson et al. 1984; Kosinski et al. 1986; Mihailoff et al. 1989). Therefore, the BPn may be the hub to the cerebellar cortex for conveying the integrated sensory inputs from the entire body. It seems plausible that the JCMS proprioception is also included in the sensory inputs.

In regard to afferent projections, as already discussed above, the Su5 received strong projections from the ipsilateral Me5 neurons, which were rostrocaudally scattered at levels from the midbrain to the rostral pons. In addition, the Su 5 received weak projections from the ipsilateral RRF. Since the RRF is involved in orofacial motor function (Arts et al. 1998; Uchida et al. 2005), this function may be mediated by the RRFSu5 route. Furthermore, the Su 5 received inputs from neurons in the DR, which is located at levels from the caudal midbrain to the rostral pons. The DR neurons contain serotonergic neurons, which are involved in mood, sleep, and modulating pain (Sanders et al. 1980; Graeff et al. 1996; Ito et al. 2013). The DR-Su5 pathway might be involved in the stress-induced involuntary movements such as bruxism and clenching.

Connections with the diencephalon. The Su5 did not receive projections from the thalamus. In contrast, the Su5 sent projections to the dorsal and ventral thalamus. For instance, the Su5 strongly projected to the contralateral VPMcvm, and weakly to the OPC, paracentral nucleus, and posterior thalamic nucleus; these projection features are consistent with those reported in our previous studies (Yoshida et al. 2017; Sato et al. 2020). The VPMcvm projects principally to the dGIrvs2 and slightly to the rostral S2, and the OPC projects to the rostral S1 and rostral S2 as well as the rostral GI (Sato et al. 2017; Tsutsumi et al. 2021). We have also found a weak projection from the Su5 to the Pf in the present study. Berendse and Groenewegen (1991) have revealed that the rat Pf projects chiefly to the rostral level of the Agl, which corresponds to the primary motor cortex in the primate (Donoghue and Wise 1982; Donoghue and Parham 1983), and slightly to the rostral part of the Agm, which corresponds to the primate premotor and 
supplementary motor cortices (Donoghue and Parham 1983; Hicks and Huerta 1991; Van Eden et al. 1992). Interestingly, we found contralateral projections from the Su 5 to the ZI, part of the ventral thalamus. The $\mathrm{ZI}$ receives heavy exteroceptive and interoceptive inputs from the spinal cord and subfornical region as well as many brainstem nuclei (for review, see Mitrofanis 2005). Thus, the ZI may be an integrative hub between the exteroception and interoception from the entire body. In summary, these findings suggest that the JCMS proprioception via the Su5 may be useful for neuronal processing of emotion, sensory integration and discrimination, and motor actions, depending on the distinctive thalamic projections.

We have also demonstrated that the Su 5 sends moderate projections to the $\mathrm{LH}$, and it receives inputs from the posterior part of ipsilateral LH, which includes the Psth. Interestingly, the hypothalamus has been reported to receive strong projections from the trigeminal sensory nuclear complex, which receives almost all of the orofacial sensation excluding the JCMS proprioception (Malick and Burstein 1998; Malick et al. 2000). Electrical stimulation of the cat LH activates the masseter muscle and facilitates the jaw-closing reflex (Landgren and Olsson 1980; Weiner et al. 1993). Goto and Swanson (2004) and Notsu et al. (2008) have also suggested that the Psth plays specific roles in central parasympathetic control. Therefore, the LH/Psth-Su5 pathways may regulate the mastication during feeding behavior.

In addition, the Su5 received ipsilateral projections from the $\mathrm{PvH}$, especially its medial parvicellular part. Physical and psychological stressors are known to activate the parvicellular $\mathrm{PvH}$ neurons (Sawchenko et al. 1996; Herman and Cullinan 1997; Thompson and Swanson 2003; Coote 2005). The PvH-Su5 pathway triggered by multiple stressors may activate premotoneurons for masticatory movements (for review, see Dubner et al. 1978; Taylor 1990). This pathway might be another route for inducing stress-induced involuntary movements.

Connections with the basal telencephalon. In the present study, the Su5 received ipsilateral projections from the dorsal part of the lateral BST (BSTI), which seemed to partly include the rhomboid subnucleus of the BST denoted by Swanson (2004). The rhomboid subnucleus of the BST ipsilaterally projects to the Su5, the Me5, the Sol, the salivary nucleus, and the ambiguus nucleus (Dong and Swanson 2003). The Su5 also received ipsilateral projections from the rostral level of the AmC. Since the BSTI and AmC are known to have similar neuronal connections with other brain regions (Alden et al. 1994; Bienkowski and Rinaman 2013), it is plausible that both the BSTI and AmC projected to the Su5. In fact, electrical stimulation of the amygdala can induce rhythmical jaw movements (Kawamura and Tsukamoto 1960; Nakamura and Kubo 1978; Sasamoto and Ohta 1982) and excite the Su5 neurons (Ohta and Moriyama 1986). Importantly, both the BSTI and AmC are thought to coordinate behavioral and physiological responses to internal and environmental stressors (Alden et al. 1994; Bienkowski and Rinaman 2013). Therefore, this BSTI/AmC-Su5 pathways activated by stressors, again, may cause involuntary movements.

Connections with the cerebral cortex. The Su5 had no projections to the cerebral cortex, whereas it received strong projections from the rostroventral S1, the rostral S2, and the GI ventrally adjacent to the 
S1 and S2 areas, bilaterally with a contralateral predominance. The Su5 also received moderate projections from the ipsilateral DP and weaker projections from the contralateral rostralmost Agl. These corticofugal pathways to the Su5 are consistent with earlier findings after injections of anterograde tracers into these cortical regions (rostroventral S1, Chang et al. 2009; Yoshida et al. 2009; Tomita et al. 2012; rostral S2, Haque et al. 2012; Gl, Sato et al. 2013; Ikenoue et al. 2018; rostralmost Agl, Yoshida et al. 2009; DP, Akhter et al. 2014). The projections from the cortical areas to the Su5 may regulate the activity of Su5 neurons, thus enabling the emotional, sensory, and motor cortices to control the orofacial movements including the jaw-movement. Especially, our previous studies (Sato et al. 2017, 2020; Tsutsumi et al. 2021) have revealed that the JCMS proprioceptive signals are transmitted from the VPMcvm and OPC to the GI, the rostral S2, and the rostroventral S1. Thus, the GI-Su5, rostral S2-Su5, and rostroventral S1-Su 5 routes may play important roles in feedback control of coordinated orofacial movements. In fact, electrical stimulation of the rostroventral S1 and the rostralmost Agl is well known to induce rhythmical jaw movements (Sasamoto et al. 1990; Satoh et al. 2007; Avivi-Arber et al. 2010; Uchino et al. 2015). On the other hand, direct projections from the cerebral cortex to cranial motoneurons (including the jaw-closing and -opening trigeminal motoneurons) are sparse in the rat (Valverde 1962; Zhang and Sasamoto 1990), suggesting that corticofugal projections to premotoneurons (i.e., the rostroventral S1-Su5 and the rostralmost Agl-Su5 projections) are subserving to induce the stimulationinduced rhythmical jaw movements. We note that electrical stimulation of the so-called P-area in the rat insular cortex is well known to induce rhythmical jaw movements (Sasamoto et al. 1990; Satoh et al. 2007); the effective stimulation sites are located in the agranular or dysgranular insular cortices, but not in the GI. Interestingly, the DP is located in the prefrontal cortex related to emotional and autonomic functions, and drives suppression of fear and drug seeking (Vidal-Gonzalez et al. 2006; Peters et al. 2009). Thus, some emotional or autonomic functions of the DP may affect the Su5 neurons through the DP-Su5 route.

\section{Declarations}

Funding

This work was supported by Grants-in-Aid for Scientific Research of the Japan Society for the Promotion of Science (18K19641, 18KK0259 to A.Y. and 17K11608, 20 K09888 to F.S.).

Conflicts of interest/Competing interests

The authors have no financial or other relationships to report that might lead to conflict interest.

Availability of data and material

All data and materials are available on request.

Code availability

Not applicable. 
Authors' contributions

All authors read and approved the final manuscript. AY and YTa conceptualized the hypothesis, designed and supervised the experiments and directed the data analysis. MI, FS, YM and YTs, carried out the experiments and data analysis. TF and KU helped with the experiments and data analysis. AY, MI, FA, YCB, YTa and TI finalized the figures and text.

Ethical approval

Detailed protocols for the care and use of laboratory animals were approved by the animal ethics committees of the Osaka University Graduate School of Dentistry.

Consent to participate

All authors agreed to participate the study.

Consent for publication

All authors agree with publication of this study.

\section{References}

1. Akhter F, Haque T, Sato F, Kato T, Ohara H, Fujio T, Tsutsumi K, Uchino K, Sessle BJ, Yoshida A (2014) Projections from the dorsal peduncular cortex to the trigeminal subnucleus caudalis (medullary dorsal horn) and other lower brainstem areas in rats. Neuroscience 266:23-37

2. Alden M, Besson JM, Bernard JF (1994) Organization of the efferent projections from the pontine parabrachial area to the bed nucleus of the stria terminalis and neighboring regions: a PHA-L study in the rat. J Comp Neurol 341:289-314

3. Altschuler SM, Bao XM, Bieger D, Hopkins DA, Miselis RR (1989) Viscerotopic representation of the upper alimentary tract in the rat: sensory ganglia and nuclei of the solitary and spinal trigeminal tracts. J Comp Neurol 283:248-268

4. Arts MPM, Bemelmans FFJ, Cools AR (1998) Role of the retrorubral nucleus in striatally elicited orofacial dyskinesia in cats: effects of muscimol and bicuculline. Psychopharmacol 140:150-156

5. Åström KE (1953) On the central course of afferent fibres in the trigeminal, facial, glossopharyngeal, and vagal nerves and their nuclei in the mouse. Acta Physiol Scand 39: Suppl 106:209-320

6. Avivi-Arber L, Lee JC, Sessle BJ (2010) Effects of incisor extraction on jaw and tongue motor representations within face sensorimotor cortex of adult rats. J Comp Neurol 518:1030-1045

7. Berendse HW, Groenewegen HJ (1991) Restricted cortical termination fields of the midline and intralaminar thalamic nuclei in the rat. Neuroscience 42:73-102

8. Bickford ME, Hall WC (1992) The nigral projection to predorsal bundle cells in the superior colliculus of the rat. J Comp Neurol 319:11-33 
9. Bienkowski MS, Rinaman L (2013) Common and distinct neural inputs to the medial central nucleus of the amygdala and anterior ventrolateral bed nucleus of stria terminalis in rats. Brain Struct Funct 218:187-208

10. Brodal P (1982) The cerebropontocerebellar pathway: Salient features of its organization. Exp Brain Res [Suppl] 6:108-133

11. Campbell SK, Parker TD, Welker W (1974) Somatotopic organization of the external cuneate nucleus in albino rats. Brain Res 77:1-23

12. Chang Z, Haque T, lida C, Seki S, Sato F, Kato T, Uchino K, Ono T, Nakamura M, Bae YC, Yoshida A (2009) Distribution of premotoneurons for jaw-closing and jaw-opening motor nucleus receiving contacts from axon terminals of primary somatosensory cortical neurons in rats. Brain Res 1275:43-53

13. Coote JH (2005) A role for the paraventricular nucleus of the hypothalamus in the autonomic control of heart and kidney. Exp Physiol 90:169-173

14. Cunningham ET Jr, Sawchenko PE (2000) Dorsal medullary pathways subserving oromotor reflexes in the rat: implications for the central neural control of swallowing. J Comp Neurol 417:448-466

15. Dong HW, Swanson LW (2003) Projections from the rhomboid nucleus of the bed nuclei of the stria terminalis: implications for cerebral hemisphere regulation of ingestive behaviors. J Comp Neurol 463:434-472

16. Donga R, Lund JP, Veilleux D (1990) An electrophysiological study of trigeminal commissural interneurons in the anaesthetized rabbit. Brain Res 515:351-354

17. Donoghue JP, Parham C (1983) Afferent connections of the lateral agranular field of the rat motor cortex. J Comp Neurol 217:390-404

18. Donoghue JP, Wise SP (1982) The motor cortex of the rat: cytoarchitecture and microstimulation mapping. J Comp Neurol 212:76-88

19. Dubner R, Sessle BJ, Storey AT (1978) The Neural Basis of Oral and Facial Function. Plenum Press, New York

20. Fujio T, Sato F, Tachibana Y, Kato T, Tomita A, Higashiyama K, Ono T, Maeda Y, Yoshida A (2016) Revisiting the supratrigeminal nucleus in the rat. Neuroscience 324:307-320

21. Graeff FG, Guimarães FS, De Andrade TG, Deakin JF (1996) Role of 5-HT in stress, anxiety, and depression. Pharmacol Biochem Behav 54:129-141

22. Goldberg LJ, Nakamura Y (1968) Lingually induced inhibition of masseteric motoneurones. Experientia 24:371-373

23. Goto M, Swanson LW (2004) Axonal projections from the parasubthalamic nucleus. J Comp Neurol 469:581-607

24. Haque T, Akhter F, Kato T, Sato F, Takeda R, Higashiyama K, Moritani M, Bae YC, Sessle BJ, Yoshida A (2012) Somatotopic direct projections from orofacial areas of secondary somatosensory cortex to trigeminal sensory nuclear complex in rats. Neuroscience 219:214-233 
25. Hattox AM, Priest CA, Keller A (2002) Functional circuitry involved in the regulation of whisker movements. J Comp Neurol 442:266-276

26. Herman JP, Cullinan WE (1997) Neurocircuitry of stress: central control of the hypothalamo-pituitaryadrenocortical axis. Trends Neurosci 20:78-84

27. Hicks RR, Huerta MF (1991) Differential thalamic connectivity of rostral and caudal parts of cortical area Fr2 in rats. Brain Res 568:325-329

28. Huerta MF, Harting JK (1984) Connectional organization of the superior colliculus. Trends Neurosci 7:286-289

29. Ikenoue E, Akhter F, Tsutsumi Y, Sato F, Ohara H, Uchino K, Furuta T, Tachibana Y, Yoshida A (2018) Transcortical descending pathways through granular insular cortex conveying orofacial proprioception. Brain Res 1687:11-19

30. Ito H, Yanase M, Yamashita A, Kitabatake C, Hamada A, Suhara Y, Narita M, Ikegami D, Sakai H, Yamazaki M, Narita M (2013) Analysis of sleep disorders under pain using an optogenetic tool: possible involvement of the activation of dorsal raphe nucleus-serotonergic neurons. Mol Brain 6:59ãahttps://doi.org/10.1186/1756-6606-6-59

31. Jerge CR (1963) The function of the nucleus supratrigeminalis. J Neurophysiol 26:393-402

32. Kawamura Y, Tsukamoto S (1960) Analysis of jaw movements from the cortical jaw motor area and amygdala. Jpn J Physiol 10:471-488

33. Kidokoro Y, Kubota K, Shuto S, Sumino R (1968) Possible interneurons responsible for reflex inhibition of motoneurons of jaw-closing muscles from the inferior dental nerve. J Neurophysiol 31:709-716

34. Kosinski RJ, Neafsey EJ, Castro AJ (1986) A comparative topographical analysis of dorsal column nuclear and cerebral cortical projections to the basilar pontine gray in rats. J Comp Neurol 244:163173

35. Landgren S, Olsson KA (1980) The effect of electrical stimulation in the hypothalamus on the monosynaptic jaw closing and the disynaptic jaw opening reflexes in the cat. Exp Brain Res 39:389400

36. Li YQ, Takada M, Kaneko T, Mizuno N (1995) Premotor neurons for trigeminal motor nucleus neurons innervating the jaw-closing and jaw-opening muscles: differential distribution in the lower brainstem of the rat. J Comp Neurol 356:563-579

37. Lorente de No'R (1922) Contribució na1 conocimientodelnervio trigé mino. Libro en honor de Dn. S. Ramón y Cajal. Madrid Mó ya 2:13

38. Lorente de No' R (1933) Vestibulo-ocular reflex arc. Arch Neurol Psychiat 30:245-291

39. Luo P, Moritani M, Dessem D (2001) Jaw-muscle spindle afferent pathways to the trigeminal motor nucleus in the rat. J Comp Neurol 435:341-353

40. Luo P, Wong R, Dessem D (1995) Projection of jaw-muscle spindle afferents to the caudal brainstem in rats demonstrated using intracellular biotinamide. J Comp Neurol 358:63-78 
41. Ma WL, Zhang WB, Xiong KH, Guo F (2007) Visceral and orofacial somatic afferent fiber terminals converge onto the same neuron in paratrigeminal nucleus: An electron microscopic study in rats. Auton Neurosci 131:45-49

42. Malick A, Burstein R (1998) Cells of origin of the trigeminohypothalamic tract in the rat. J Comp Neurol 400:125-144

43. Malick A, Strassman RM, Burstein R (2000) Trigeminohypothalamic and reticulohypothalamic tract neurons in the upper cervical spinal cord and caudal medulla of the rat. J Neurophysiol 84:20782112

44. Mascaro MB, Prosdo'cimi FC, Bittencourt JC, Elias CF (2009) Forebrain projections to brainstem nuclei involved in the control of mandibular movements in rats. Eur J Oral Sci 117:676-684

45. Mihailoff GA, Kosinski RJ, Azizi SA, Border BG (1989) Survey of noncortical afferent projections to the basilar pontine nuclei: a retrograde tracing study in the rat. J Comp Neurol 282:617-643

46. Mitrofanis J (2005) Some certainty for the "zone of uncertainty"? Exploring the function of the zona incerta. Neuroscience 130:1-15

47. Miyazaki R, Luschei ES (1987) Responses of neurons in nucleus supratrigeminalis to sinusoidal jaw movements in the cat. Exp Neurol 96:145-157

48. Mizuno N (1970) Projection fibers from the main sensory trigeminal nucleus and the supratrigeminal region. J Comp Neurol 139:457-471

49. Nakamura S, Inoue T, Nakajima K, Moritani M, Nakayama K, Tokita K, Yoshida A, Maki K (2008) Synaptic transmission from the supratrigeminal region to jaw-closing and jaw-opening motoneurons in developing rats. J Neurophysiol 100:1885-1896

50. Nakamura Y, Kubo Y (1978) Masticatory rhythm in intracellular potential of trigeminal motoneurons induced by stimulation of orbital cortex and amygdala in cats. Brain Res 14:504-509

51. Nonaka M, Nishimura A, Nakamura S, Nakayama K, Mochizuki A, lijima T, Inoue T (2012) Convergent pre-motoneuronal inputs to single trigeminal motoneurons. J Dent Res 91:888-893

52. Notsu K, Tsumori T, Yokota S, Sekine J, Yasui Y (2008) Posterior lateral hypothalamic axon terminals are in contact with trigeminal premotor neurons in the parvicellular reticular formation of the rat medulla oblongata. Brain Res 1244:71-81

53. Ohta M, Moriyama Y (1986) Supratrigeminal neurons mediate the shortest, disynaptic pathway from the central amygdaloid nucleus to the contralateral trigeminal motoneurons in the rat. Comp Biochem Physiol A Comp Physiol 83:633-641

54. Oka A, Yamamoto M, Takeda R, Ohara H, Sato F, Akhter F, Haque T, Kato T, Sessle BJ, Takada K, Yoshida A (2013) Jaw-opening and -closing premotoneurons in the nucleus of the solitary tract making contacts with laryngeal and pharyngeal afferent terminals in rats. Brain Res 1540:48-63

55. Paik SK, Lee HJ, Choi MK, Cho YS, Park MJ, Moritani M, Yoshida A, Kim YS, Bae YC (2009) Ultrastructural analysis of glutamate-, GABA-, and glycine-immunopositive boutons from supratrigeminal premotoneurons in the rat trigeminal motor nucleus. J Neurosci Res 87:1115-1122 
56. Papp RS, Palkovits M (2014) Brainstem projections of neurons located in various subdivisions of the dorsolateral hypothalamic area-an anterograde tract-tracing study. Front Neuroanat 8:34. https://www.doi.org/10.3389/fnana.2014.00034

57. Paxinos G, Watson C (1986) The Rat Brain in Stereotaxic Coordinates, 2nd edn. Academic Press, Sydney

58. Paxinos G, Watson C (1998) The Rat Brain in Stereotaxic Coordinates, 4th edn. Academic Press, Sydney

59. Paxinos G, Watson C (2014) The Rat Brain in Stereotaxic Coordinates, 7th edn. Academic Press, Sydney

60. Peters J, Kalivas PW, Quirk GJ (2009) Extinction circuits for fear and addiction overlap in prefrontal cortex. Learn Mem 16:279-288

61. Phelan KD, Falls WM (1989) The interstitial system of the spinal trigeminal tract in the rat: anatomical evidence for morphological and functional heterogeneity. Somatosens Mot Res 6:367399

62. Porter JD, Donaldson IM (1991) The anatomical substrate for cat extraocular muscle proprioception. Neuroscience 43:473-483

63. Rosén I, Sjölund B (1973) Organization of group I activated cells in the main and external cuneate nuclei of the cat: identification of muscle receptors. Exp Brain Res 16:221-237

64. Rokx JT, van Willigen JD, Jüch PJ (1986) Bilateral brainstem connections of the rat supratrigeminal region. Acta Anat (Basel) 127:16-21

65. Sanders KH, Klein CE, Mayor TE, Heym C, Handwerker HO (1980) Differential effects of noxious and non-noxious input on neurones according to location in ventral periaqueductal grey or dorsal raphe nucleus. Brain Res 186:83-97

66. Sasamoto K, Ohta M (1982) Amygdaloid-induced jaw opening and facilitation or inhibition of the trigeminal motoneurons in the rat. Comp Biochem Physiol A Comp Physiol 73:349-354

67. Sasamoto K, Zhang G, Iwasaki M (1990) Two types of rhythmical jaw movements evoked by stimulation of the rat cortex. Jpn J Oral Biol 32:57-68

68. Sato F, Akhter F, Haque T, Kato T, Takeda R, Nagase Y, Sessle BJ, Yoshida A (2013) Projections from the insular cortex to pain- receptive trigeminal caudal subnucleus (medullary dorsal horn) and other lower brainstem areas in rats. Neuroscience 233:9-27

69. Sato F, Kado S, Tsutsumi Y, Tachibana Y, Ikenoue E, Furuta T, Uchino K, Bae YC, Uzawa N, Yoshida A (2020) Ascending projection of jaw-closing muscle-proprioception to the intralaminar thalamic nuclei in rats. Brain Res 1739:146830. https://doi.org/10.1016/j.brainres.2020.146830

70. Sato F, Uemura Y, Kanno C, Tsutsumi Y, Tomita A, Oka A, Kato T, Uchino K, Murakami J, Haque T, Tachibana Y, Yoshida A (2017) Thalamo-insular pathway conveying orofacial muscle proprioception in the rat. Neuroscience 365:158-178 
71. Satoh Y, Ishizuka K, Murakami T (2007) Changes in cortically induced rhythmic jaw movements after lesioning of the red nucleus in rats. Brain Res 1165:60-70

72. Sawchenko PE, Brown ER, Chan RK, Ericsson A, Li HY, Roland BL, Kovacs KJ (1996) The paraventricular nucleus of the hypothalamus and the functional neuroanatomy of visceromotor responses to stress. Prog Brain Res 107:201-222

73. Shammah-Lagnado SJ, Alheid GF, Heimer L (2001) Striatal and central extended amygdala parts of the interstitial nucleus of the posterior limb of the anterior commissure: evidence from tract-tracing techniques in the rat. J Comp Neurol 439:104-126

74. Shigenaga Y, Doe K, Suemune S, Mitsuhiro Y, Tsuru K, Otani K, Shirana Y, Hosoi M, Yoshida A, Kagawa K (1989) Physiological and morphological characteristics of periodontal mesencephalic trigeminal neurons in the cat -intra-axonal staining with HRP. Brain Res 505:91-110

75. Shigenaga Y, Mitsuhiro Y, Shirana Y, Tsuru H (1990) Two types of jaw-muscle spindle afferents in the cat as demonstrated by intra-axonal staining with HRP. Brain Res 514:219-237

76. Shigenaga Y, Mitsuhiro Y, Yoshida A, Cao CQ, Tsuru H (1988b) Morphology of single mesencephalic trigeminal neurons innervating masseter muscle of the cat. Brain Res 445:392-399

77. Shigenaga Y, Sera M, Nishimori T, Suemune S, Nishimura M, Yoshida A, Tsuru K (1988a) The central projection of masticatory afferent fibers to the trigeminal sensory nuclear complex and upper cervical spinal cord. J Comp Neurol 268:489-507

78. Shimizu K, Asano M, Kitagawa J, Ogiso B, Ren K, Oki H, Matsumoto M, Iwata K (2006) Phosphorylation of extracellular signal-regulated kinase in medullary and upper cervical cord neurons following noxious tooth pulp stimulation. Brain Res 1072:99-109

79. Stanek IVE, Cheng S, Takatoh J, Han BX, Wang F (2014) Monosynaptic premotor circuit tracing reveals neural substrates for oro-motor coordination. eLife 3:e02511. https://doi.org/10.7554/eLife.02511

80. Swanson LW (2004) Brain maps: Structure of the rat brain. A laboratory guide with printed and electronic templates for data, models and schematics, 3rd edn. Elsevier, Amsterdam

81. Swenson RS, Kosinski RJ, Castro AJ (1984) Topography of spinal, dorsal column nuclear, and spinal trigeminal projections to the pontine gray in rats. J Comp Neurol 222:301-311

82. Takata M, Kawamura Y (1970) Neurophysiologic properties of the supratrigeminal nucleus. Jap J Physiol 20:1-11

83. Takemura M, Sugimoto T, Shigenaga $Y$ (1991) Difference in central projection of primary afferents innervating facial and intraoral structures in the rat. Exp Neurol 111:324-331

84. Taylor A (1990) Neurophysiology of the Jaws and Teeth. Macmillan Press, London

85. Ter Horst GJ, Copray JC, Liem RS, Van Willigen JD (1991) Projections from the rostral parvocellular reticular formation to pontine and medullary nuclei in the rat: involvement in autonomic regulation and orofacial motor control. Neuroscience 40:735-758 
86. Tomita A, Kato T, Sato F, Haque T, Oka A, Yamamoto M, Ono T, Bae YC, Maeda Y, Sessle BJ, Yoshida A (2012) Somatotopic direct projections from orofacial areas of primary somatosensory cortex to pons and medulla, especially to trigeminal sensory nuclear complex, in rats. Neuroscience 200:166185

87. Thompson RH, Swanson LW (2003) Structural characterization of a hypothalamic visceromotor pattern generator network. Brain Res Brain Res Rev 41:153-202

88. Torvik A (1956) Afferent connections to the sensory trigeminal nuclei, the nucleus of the solitary tract and adjacent structures. J Comp Neurol 106:51-141

89. Travers JB, Norgren R (1983) Afferent projections to the oral motor nuclei in the rat. J Comp Neurol 220:280-298

90. Tsutsumi Y, Mizuno Y, Haque H, Sato F, Furuta T, Oka A, Moritani M, Bae YC, Yamashiro T, Tachibana Y, Yoshida A (2021) Widespread corticopetal projections from the oval paracentral nucleus of the intralaminar thalamic nuclei conveying orofacial proprioception in rats. Brain Struct Funct 226:1115-1133

91. Uchida T, Adachi K, Fujita S, Lee J, Gionhaku N, Cools AR, Koshikawa N (2005) Role of GABA receptors in the retrorubral filed and ventral pallidum in rat jaw movements elicited by dopaminergic stimulation of the nucleus accumbens shell. Eur J Pharmacol 510:39-47

92. Uchino K, Higashiyama K, Kato T, Haque T, Sato F, Tomita A, Tsutsumi K, Moritani M, Yamamura K, Yoshida A (2015) Jaw movement-related primary somatosensory cortical area in the rat. Brain Res 284:55-64

93. Uemura Y, Haque T, Sato F, Tsutsumi Y, Ohara H, Oka A, Furuta T, Bae YC, Yamashiro T, Tachibana Y, Yoshida A (2020) Proprioceptive thalamus receiving forelimb and neck muscle spindle inputs via the external cuneate nucleus in the rat. Brain Struct Funct 225:2177-2192

94. Valverde F (1962) Reticular formation of the albino rat's brain stem cytoarchitecture and corticofugal connections. J Comp Neurol 119:25-53

95. VanderWerf F, Aramideh M, Ongerboer de Visser BW, Baljet B, Speelman JD, Otto AJ (1997) A retrograde double fluorescent tracing study of the levator palpebrae superioris muscle in the cynomolgus monkey. Exp Brain Res 113:174-179

96. Van Eden CG, Lamme VA, Uylings HB (1992) Heterotopic cortical afferents to the medial prefrontal cortex in the rat. A combined retrograde and anterograde tracer study. Eur J Neurosci 4:77-97

97. Vidal-Gonzalez I, Vidal-Gonzalez B, Rauch SL, Quirk GJ (2006) Microstimulation reveals opposing influences of prelimbic and infralimbic cortex on the expression of conditioned fear. Learn Mem $13: 728-733$

98. Weiner S, Shaikh MB, Siegel A (1993) Electromyographic activity in the masseter muscle resulting from stimulation of hypothalamic behavioral sites in the cat. J Orofac Pain 7:370-377

99. Wiesendanger R, Wiesendanger M (1982) The corticopontine system in the rat. II. The projection pattern. J Comp Neurol 208:227-238 
100. Yamamoto M, Moritani M, Chang Z, Taki I, Tomita A, Ono T, Bae YC, Shigenaga Y, Yoshida A (2007) The somatotopic organization of trigeminal premotoneurons in the cat brainstem. Brain Res 1149:111-117

101. Yasui Y, Kayahara T, Shiroyama T, Nakano K (1993) Neurons in the intertrigeminal region of the rat send projection fibers to the superior colliculus. Neurosci Lett 159:39-42

102. Yasui Y, Tsumori T, Ando A, Domoto T (1995) Demonstration of axon collateral projections from the substantia nigra pars reticulata to the superior colliculus and the parvicellular reticular formation in the rat. Brain Res 674:122-126

103. Yasui Y, Tsumori T, Ando A, Domoto T, Kayahara T, Nakano K (1994) Descending projections from the superior colliculus to the reticular formation around the motor trigeminal nucleus and the parvicellular reticular formation of the medulla oblongata in the rat. Brain Res 656:420-426

104. Yoshida A, Fujio T, Sato F, Ali MS, Haque T, Ohara H, Moritani M, Kato T, Dostrovsky JO, Tachibana Y (2017) Orofacial proprioceptive thalamus of the rat. Brain Struct Funct 222:2655-2669

105. Yoshida A, Taki I, Chang Z, lida C, Haque T, Tomita A, Seki S, Yamamoto S, Masuda Y, Moritani M, Shigenaga $Y$ (2009) Corticofugal projections to trigeminal motoneurons innervating antagonistic jaw muscles in rats as demonstrated by anterograde and retrograde tract tracing. J Comp Neurol 514:368-386

106. Zhang GX, Sasamoto K (1990) Projections of two separate cortical areas for rhythmical jaw movements in the rat. Brain Res Bull 24:221-230

107. Zhou Q, Imbe H, Dubner R, Ren K (1999) Persistent Fos protein expression after orofacial deep or cutaneous tissue inflammation in rats: implications for persistent orofacial pain. J Comp Neurol 412:276-291

\section{Figures}


a
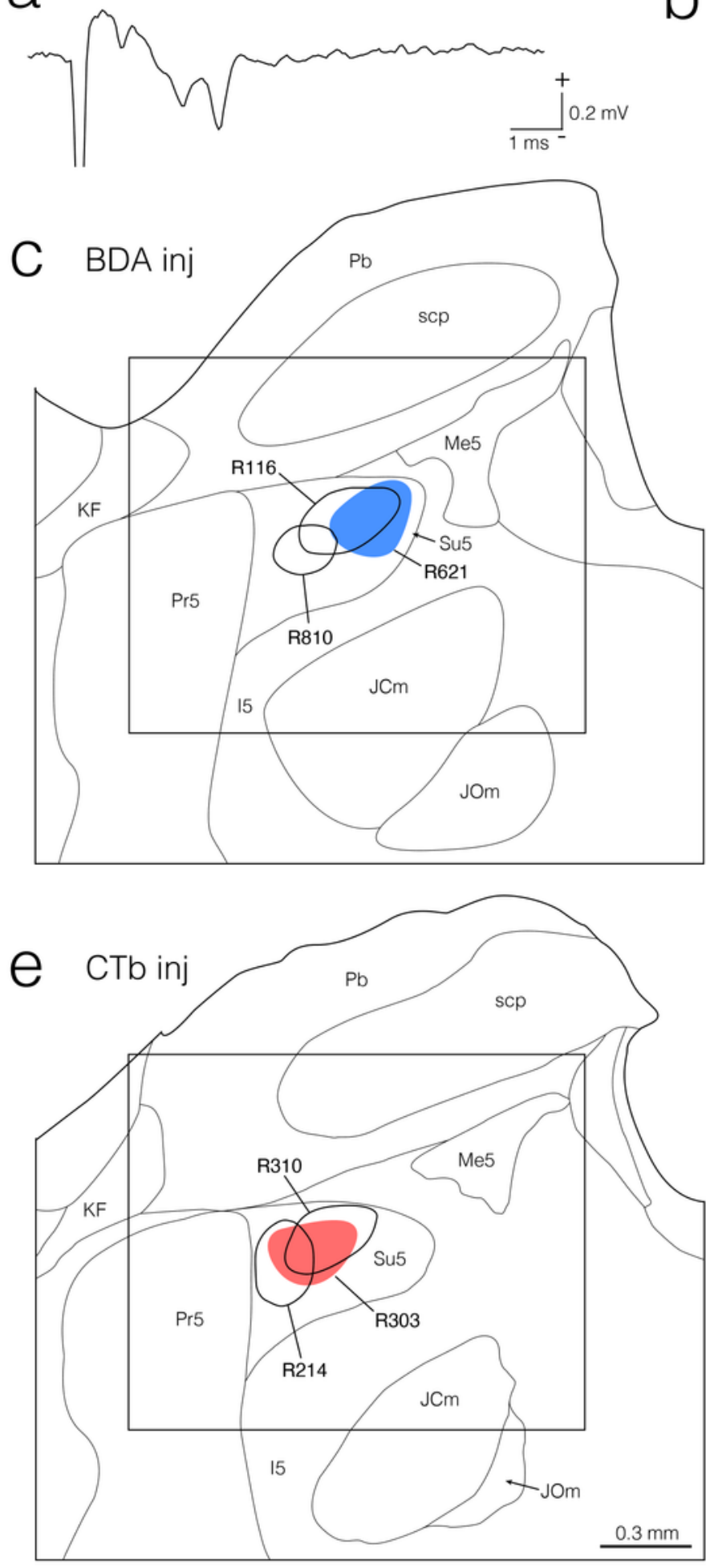

b

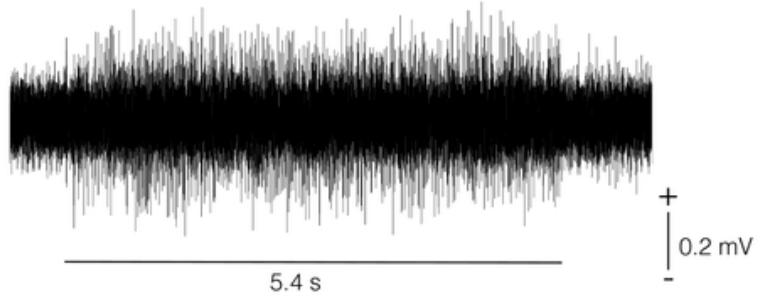

d

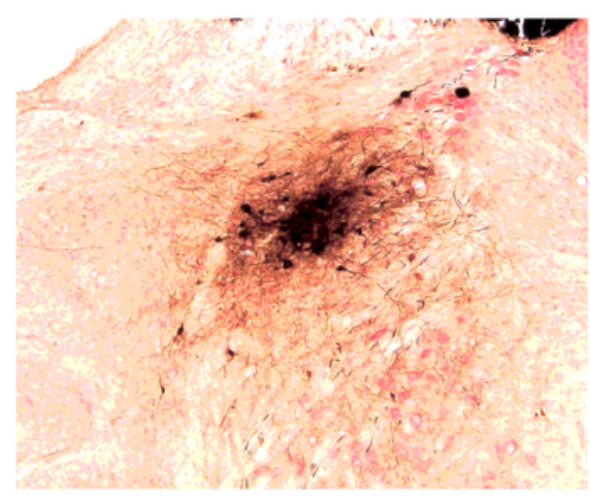

$f$

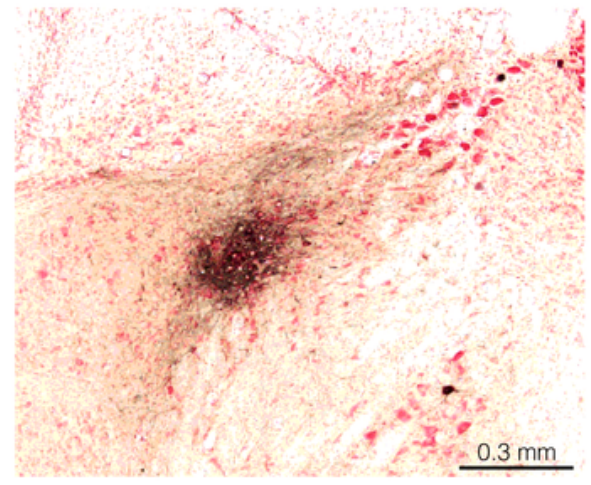

\section{Figure 1}

Field potentials recorded in the supratrigeminal nucleus (Su5) ( $a, b)$ and injection sites made at the recording sites with an anterograde tracer, biotinylated dextranamine (BDA) (c, d) or a retrograde tracer, cholera toxin $B$ subunit $(\mathrm{CTb})(\mathrm{e}, \mathrm{f})$. a: Field potentials evoked by electrical stimulation of the ipsilateral masseter nerve in a representative rat R621. b: Extracellular multi-unit discharges recorded during a sustained jaw-opening (for $5.4 \mathrm{~s}$, indicated by horizontal line) in the same representative rat R621. c-f: 
Locations of three BDA injection sites (c) and three CTb injection sites (e), indicated by respective rat numbers; injection sites of rats R621 and R303 are denoted by a blue area in c and a red area in e, respectively, and also in Fig. 4i. These injection sites are well confined in the electrophysiologically and cytoarchitectonically identified Su5. Areas boxed in c and e correspond to the photomicrographic images $d$ and $f$ of injection sites in rats R621 and R303, respectively. Sections $d$ and $f$ are counterstained with neutral red. For abbreviations, see the abbreviations list.

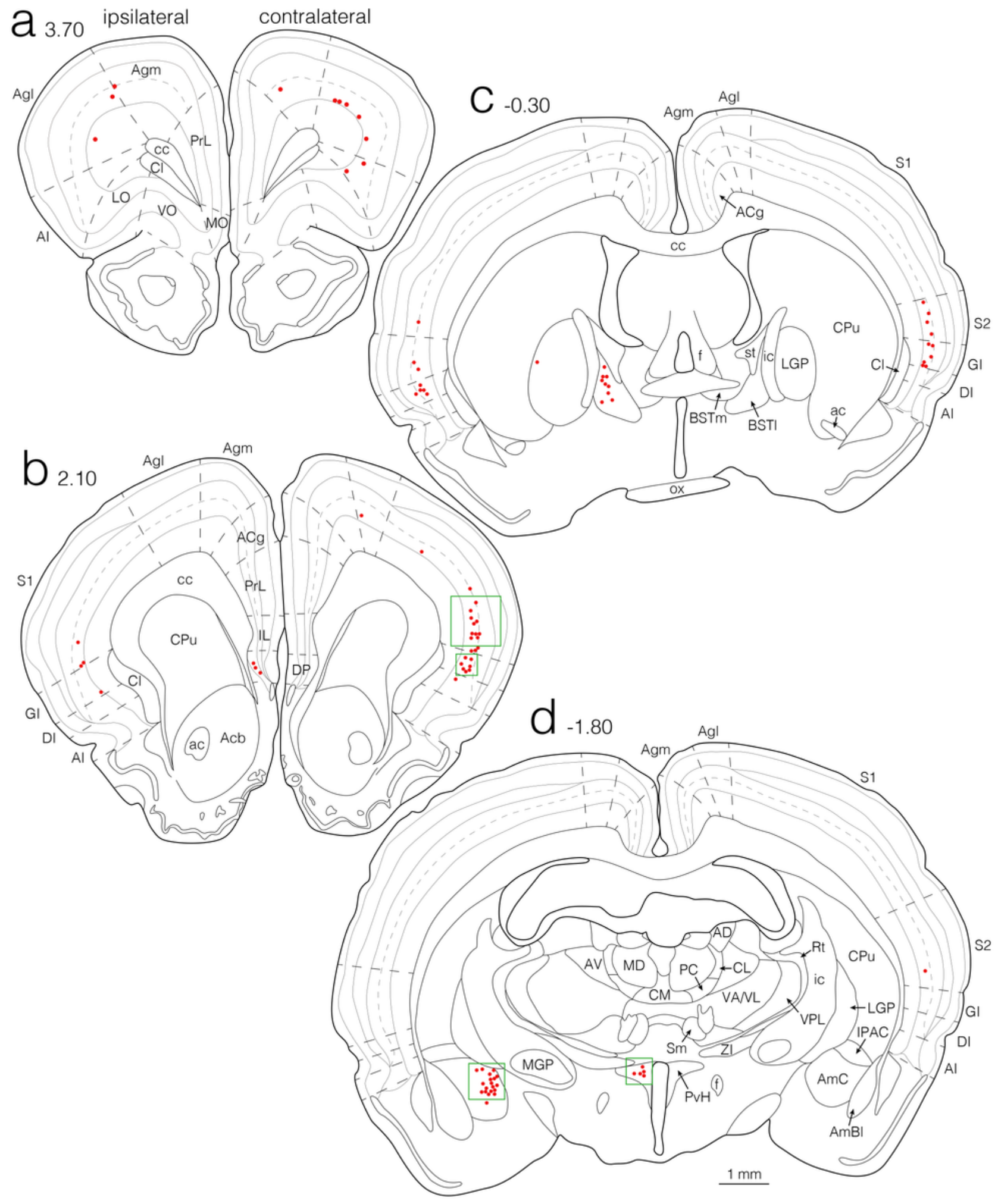

Figure 2 
Semi-schematic drawings showing the distribution of retrogradely labeled neuronal cell bodies (large red dots) after a CTb injection into the Su5 in rat R303. The CTb injection site is denoted by a red area in Figs. $1 \mathrm{e}$ and $4 \mathrm{i}$, and its photomicrograph is shown in Fig. $1 \mathrm{f}$. Coronal sections are arranged rostrocaudally from a to $\mathrm{d}$. The left side of each drawing corresponds to the side ipsilateral to the injection sites. Number upper-left to ipsilateral section of each drawing denotes the distance in millimeters rostral or caudal (-) to bregma. The green boxed areas in $b$ and $d$ correspond to the areas presented in photomicrographs $6 a-d$. Note that anterogradely labeled axon fibers and terminals were not observed at levels a-d after a BDA injection into the Su5 in rat R621. For abbreviations, see the abbreviations list. 


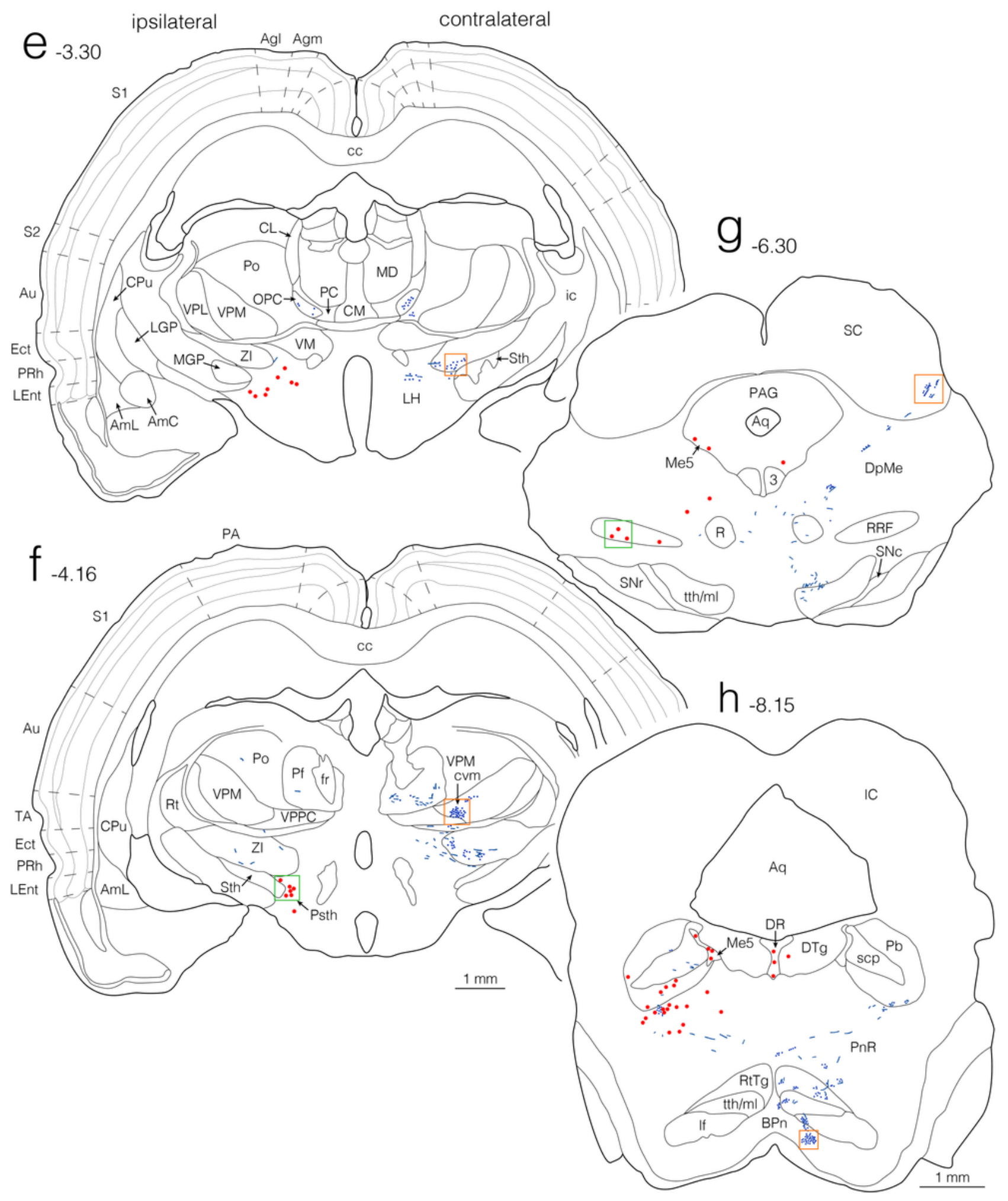

Figure 3

Semi-schematic drawings of sections that continue to Fig. 2 d. Coronal sections are arranged rostrocaudally from e to $\mathrm{h}$. Anterogradely labeled axon fibers and terminals (blue lines and small blue dots) after a BDA injection into the Su5 in rat R621 and retrogradely labeled neuronal cell bodies (large red dots) after a CTb injection into the Su 5 in rat R303 are superimposed; the labeled neuronal cell bodies observed in rat R303 are plotted at the corresponding positions on the drawings of coronal sections 
obtained in rat R621. The BDA injection site is denoted by a blue area in Figs. $1 \mathrm{c}$ and $4 \mathrm{i}$, and its photomicrograph is shown in Fig. 1d. The orange boxed areas in e-h correspond to the areas presented in photomicrographs $5 a-d$, and the green boxed areas in $f$ and $g$ correspond to the areas presented in photomicrographs $6 \mathrm{e}$ and f. For more information, see the Fig. 2 legend.

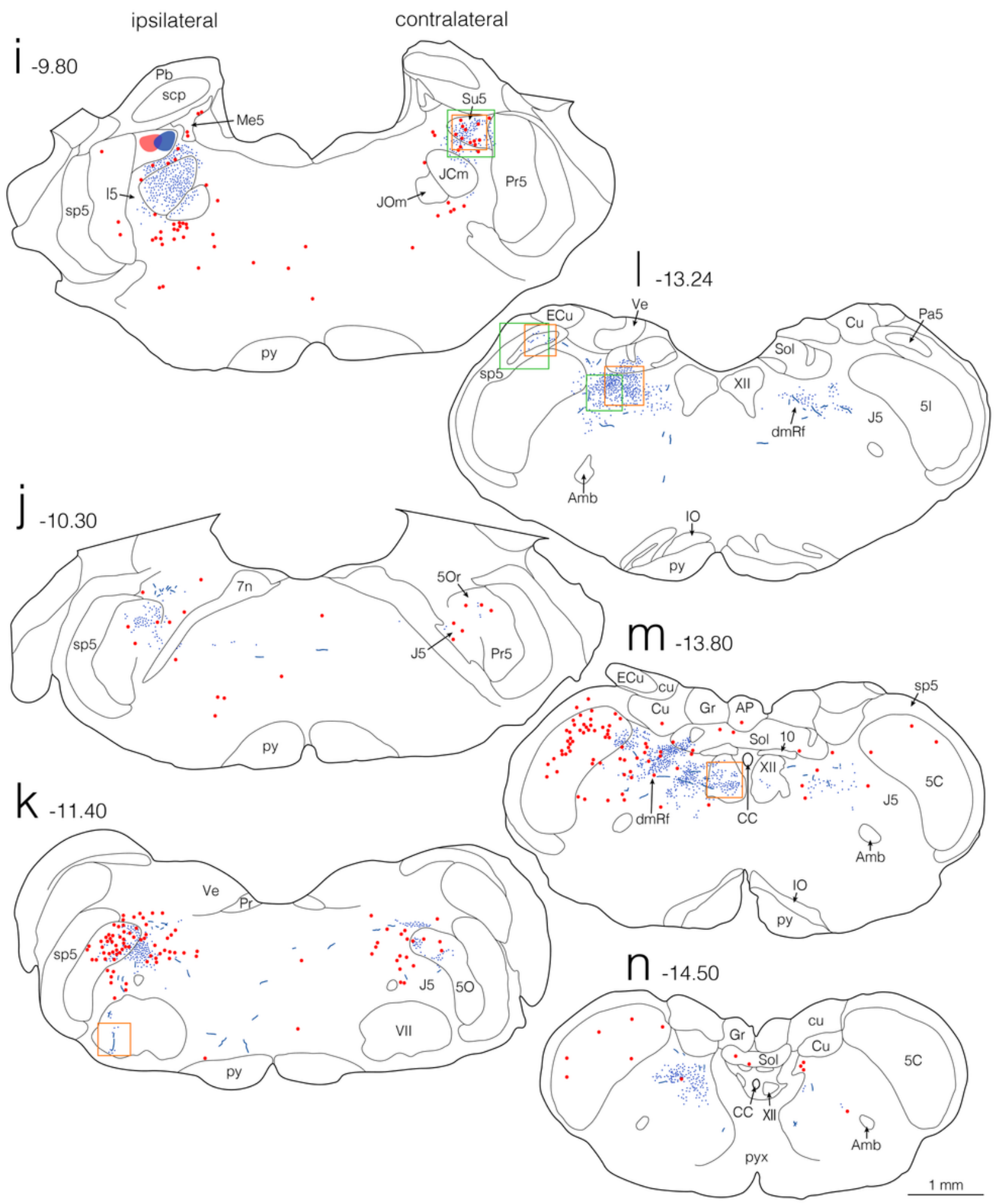

Figure 4 
Semi-schematic drawings of sections that continue to Fig. 3h. Coronal sections are arranged rostrocaudally from $\mathrm{i}$ to $\mathrm{n}$. The BDA and CTb injection sites are denoted by blue and red areas, respectively, in $\mathrm{i}$. The orange boxed areas in $\mathrm{i}$ and $\mathrm{k}-\mathrm{m}$ correspond to the areas presented in photomicrographs $5 \mathrm{e}-\mathrm{i}$, and the green boxed areas in $\mathrm{i}$ and $\mathrm{I}$ correspond to the areas presented in photomicrographs $6 \mathrm{~g}-\mathrm{i}$. For more information, see the legends for Figs. 2 and 3.

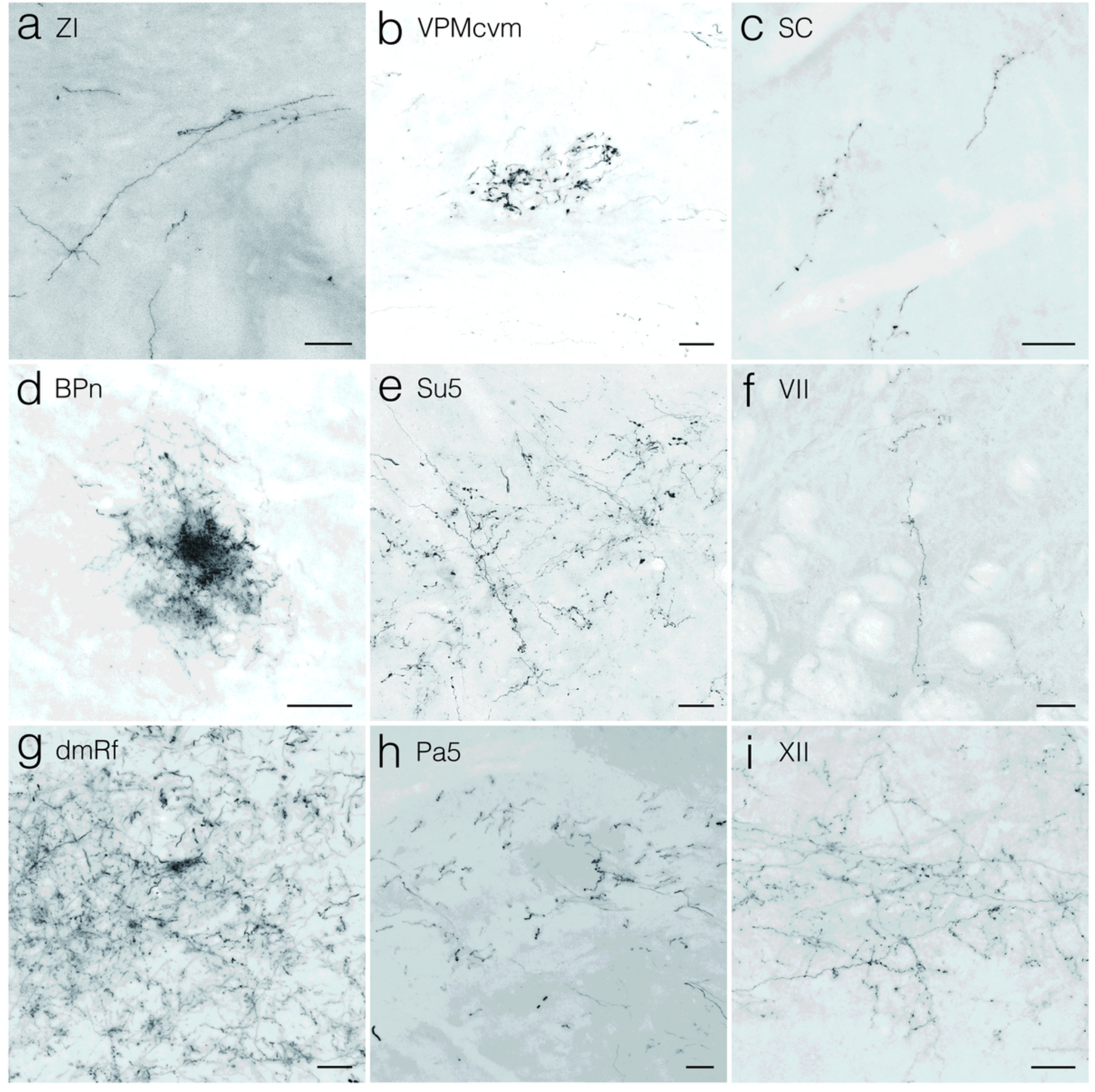

Figure 5 
Photomicrographs showing anterogradely BDA-labeled axonal fibers and terminals after a BDA injection into the Su5 in rat R621, which were found in the zona incerta (ZI) (a), caudo-ventromedial edge of the ventral posteromedial thalamic nucleus (VPMcvm) (b), superior colliculus (SC) (c), basilar pontine nuclei (BPn) (d), Su5 (e), facial nucleus (VII) (f), dorsal medullary reticular formation (dmRf) (g), paratrigeminal nucleus (Pa5) (h), and hypoglossal nucleus (XII) (i). Areas in a-i correspond to the areas shown in the orange boxes in Figs. 3e, f, g, h, 4i, k, I (lower-right box), I (upper-left box), and m, respectively. Scale bars = $50 \mu \mathrm{m}$.

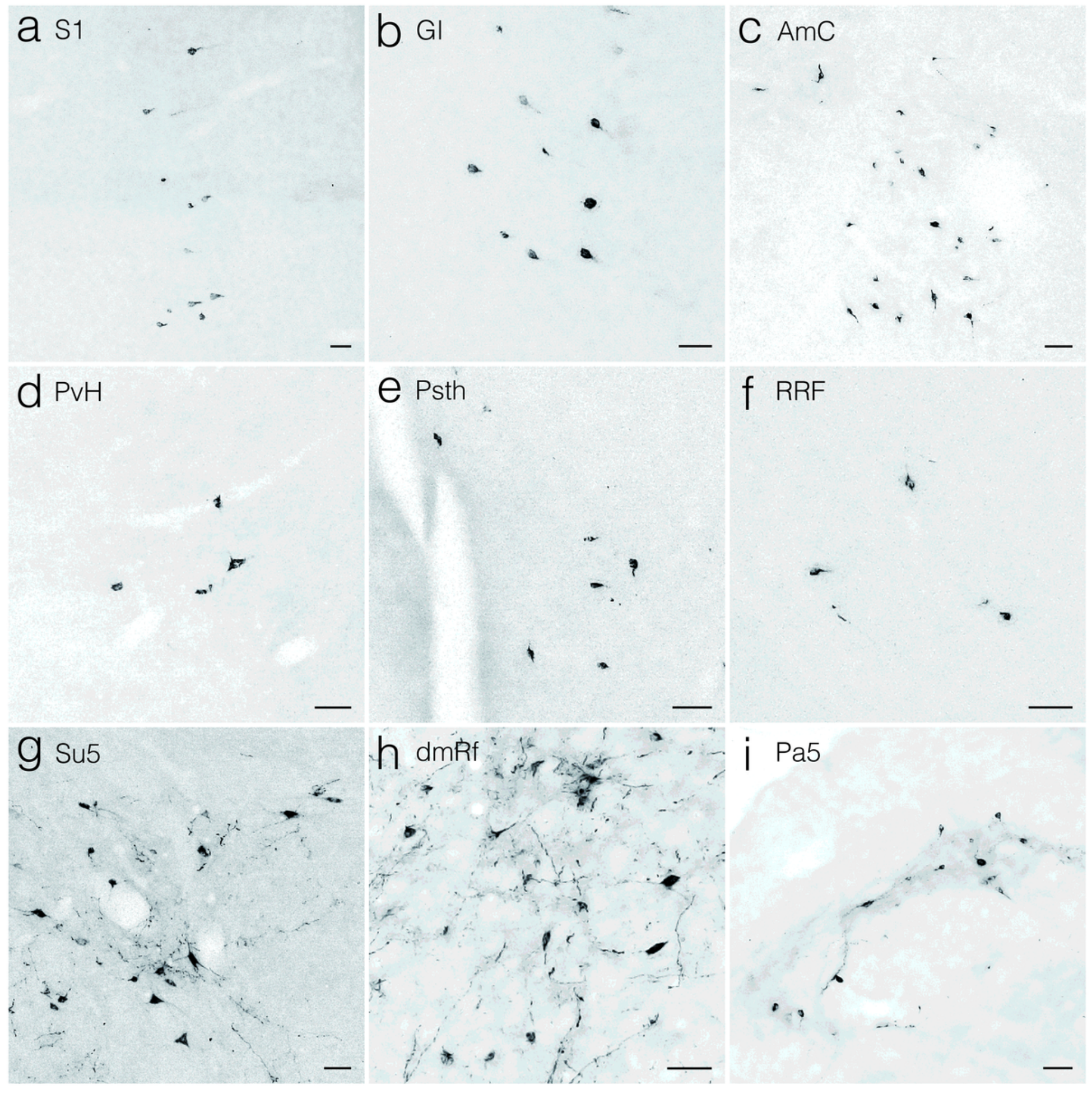

Figure 6 
Photomicrographs showing retrogradely CTb-labeled neuronal cell bodies after a CTb injection into the Su5 in rat R303, which were found in the primary somatosensory cortex (S1) (a), granular insular cortex (GI) (b), central amygdaloid nucleus (AmC) (c), paraventricular hypothalamic nucleus (PvH) (d), parasubthalamic nucleus (Psth) (e), retrorubral field (RRF) (f), Su5 (g), dmRf (h), and Pa5 (i). Areas in a-i correspond to the areas shown in the green boxes in Figs. 2b (upper box), 2b (lower box), $d$ (left box), $d$ (right box), 3f, g, 4i, I (lower-right box), and I (upper-left box), respectively. Scale bars $=50 \mu \mathrm{m}$. 